Jurnal Bimbingan dan Konseling Ar-Rahman
Volume 5, Nomor 2, Tahun 2019
Tersedia Online: http://ojs.uniska.ac.id/index.php/BKA
e-ISSN 2477-6300

\title{
LAYANAN KONSELING KELOMPOK DENGAN TEKNIK CINEMATHERAPHY UNTUK MENINGKATKAN KEDISIPLINAN SISWA DI KELAS VII C SMP NEGERI 31 BANJARMASIN
}

\author{
Husnul Khatimah, Farial, Eka Sri Handayani \\ Universitas Islam Kalimantan Muhammad Arsyad Al-Banjari \\ husnulaas@gmail.com
}

\begin{abstract}
ABSTRAK
Penelitian ini bertujuan untuk mengetahui tingkat kedisiplinan siswa sebelum dilaksanakan konseling kelompok dengan teknik cinematheraphy serta untuk mengetahui tingkat kedisiplinan siswa setelah melaksanakan konseling kelompok dengan teknik cinematheraphy dan untuk mengetahui apakah kedisiplinan siswa dapat ditingkatkan melalui konseling kelompok teknik cinematheraphy pada siswa. Penelitian menggunakan preeksperimental design yaitu one-group pretest dan posttest design. Prosedur penelitian pretest-treatment-posttest. Teknik pengambilan sampel menggunakan purposive sampling. Sampel 8 responden dari 28 populasi. Teknik pengumpulan data menggunakan skala pengukuran melalui angket. Validitas angket menggunakan Pearson Correlation dan reliabilitas menggunakan alpha cronbach. Teknik analisis data menggunakan hitungan statistik deskriptif, dan uji wilcoxon dengan aplikasi IBM SPSS Statistik 25. Hasil pretest siswa ditemukan 8 siswa dengan skor terendah. Hasil posttest siswa ada peningkatan skor dari 8 siswa. Perhitungan uji wilcoxon pada data keseluruhan diperoleh nilai signifikansi (Sig). Sebesar 0,005 kurang dari 0,05. Hal ini berarti ada pengaruh konseling kelompok dengan teknik cinematheraphy.
\end{abstract}

Kata Kunci: Konseling Kelompok; Cinematheraohy; Kedisiplinan

\begin{abstract}
This study aims to determine the level of student discipline before group counseling with cinematheraphy techniques and to determine the level of student discipline after conducting group counseling with cinematheraphy techniques and to find out whether student discipline can be improved through group counseling cinematheraphy techniques to students. The study used a pre-experimental design namely one-group pretest and posttest design. Pretest-treatment-posttest research procedure. The sampling technique uses purposive sampling. Sample 8 respondents from 28 populations. Data collection techniques using a measurement scale through a questionnaire. The validity of the questionnaire using Pearson Correlation and reliability using alpha cronbach. Data analysis techniques using descriptive statistical calculations, and Wilcoxon test with the application of IBM SPSS Statistics 25. The results of student pretest found 8 students with the lowest score. The students' posttest results increased scores from 8 students. Wilcoxon test calculations on the overall data obtained significance value (Sig). For 0.005 is less than 0.05. This means there is an influence of group counseling with cinematherapy techniques.
\end{abstract}

Keywords: Group Counseling, Cinematheraphy, Discipline 
Husnul Khatimah, Farial, Eka Sri Handayani

Jurnal Bimbingan dan Konseling Ar-Rahman

Volume 5, Nomor 2, Tahun 2019

e-ISSN 2477-6300

\section{PENDAHULUAN}

Di era globalisasi ini pendidikan sangat diperlukan untuk memajukan serta mencerdaskan kehidupan bangsa, pendidikan disepakati oleh banyak ahli memiliki peran yang besar dalam penyediaan sumber daya manusia yang berkualitas dan daya saing yang tinggi. Lamanya menempuh pendidikan dinilai memiliki banyak pengaruh terhadap pembentukan daya saing seseorang, Disiplin merupakan kunci sukses, sebab dalam disiplin akan tumbuh sifat yang teguh dalam menyatakan kebenaran, dan pada akhirnya mau berkorban untuk kepentingan bangsa dan negara. Pranawangsih (dalam Handoyo, 2009 : 31). Namun didalam pendidikan selalu saja ada problematika yang terjadi, problematika yang sering terjadi biasanya berkenaan dengan kegagalan siswa dalam bersikap disiplin.

Disiplin merupakan bentuk perilaku patuh dan tunduk terhadap peraturan yang berlaku tetapi kepatuhan itu lebih ditekankan pada kesadaran diri, bukan paksaan dari orang lain. Akan tetapi pada kenyataannya banyak perilaku disiplin manusia yag dilatarbelakangi karena adanya paksaan atau aturan yang mengekang sehingga asumsi yang berkembang dimasyarat bahwa disiplin itu berarti kaku dan menakutkan. Terdapat banyak alasan mengapa sesorang tidak bisa berperilaku disiplin, diantaranya adalah malas, belum terbiasa dengan disiplin, dia belum mampu bersikap tegas pada diri sendiri. Disiplin adalah sebagai pengawasan terhadap diri pribadi untuk melaksanakan segala sesuatu yang telah disetujui atau diterima sebagai tanggung jawab. disiplin merupakan hal yang sangat penting untuk kesuksesan bagi kegiatan belajar siswa di sekolah, karena dengan disiplin maka terciptanya rasa nyaman dan aman baik bagi diri siswa sendiri maupun bagi siswa yang lain serta orang yang berada disekitar lingkungan sekolah tersebut, kedisiplinan tidak akan bisa muncul begitu saja pada diri siswa, tanpa didasari dengan penegakan peraturan yang berupa tata tertib secara baik dan benar. Untuk membiasakan kedisiplinan siswa maka perlu banyak pihak yang harus berpartisipasi agar tercapainya suatu kedisiplinan.

Sesuai dengan penelitian Noviani (2012) Proses disiplin belajar dilalui seseorang melalui tahapan latihan atau belajar. Disiplin belajar awalnya memang berat tapi bila kita sudah berhasil mempelajari atau berlatih, kita akan dapat mengikuti dengan sendirinya tanpa merasa tertekan. Berdasarkan hasil wawancara dengan guru BK di SMA Negeri 1 Kalirejo pada penelitian awal, beberapa siswa memiliki kedisiplinan belajar yang rendah. Kedisiplinan belajar siswa yang rendah antara lain: membolos saat jam pelajaran berlangsung, mengobrol di kelas saat guru sedang menjelaskan materi, memainkan Handphone saat proses belajar mengajar, mengerjakan PR di sekolah. Disiplin belajar pada siswa dipengaruhi oleh beberapa faktor. Faktor -faktor yang mempengaruhi belajar dibedakan menjadi dua golongan: (1) faktor yang ada pada diri individu, dan (2) faktor yang ada di luar individu atau faktor sosial. Yang termasuk faktor indivisual antara lain: faktor kematangan, pertumbuhan, kecerdasan, latihan, motivasi, dan faktor pribadi. Sedangkan yang termasuk faktor sosial antara lain faktor keluarga, keadaan rumah tangga, guru dan cara mengajarnya, alat-alat yang dipergunakan dalam belajar mengajar, lingkungan, dan kesempatan yang tersedia, dan motivasi sosial (Purwanto, 1998:102).

Nursito (dalam Tarmizi, 2013) Mengemukakan bahwa "masalah kedisiplinan siswa menjadi sangat berarti bagi kemajuan sekolah". Di sekolah yang tertib akan selalu menciptakan proses pembelajaran yang baik dan efektif, sebaliknya jika pada sekolah yang tidak tertib kondisinya akan jauh berbeda. Pelanggaran- pelanggaran yang terjadi sudah dianggap biasa dan untuk memperbaiki keadaan yang demikian tidaklah mudah. Di era globalisasi ini permasalahan siswa semakinn beragam sehingga jalan pikiran siswa menjadi terbagi dengan masalah diluar sekolah dan didalam sekolah. SMP Negeri 31 Banjarmasin adalah Sekolah Menengah Pertama dengan status Negeri di kota Banjarmasin. Sebagian besar siswa disekolah ini berasal dari kalangan keluarga menengah kebawah, meskipun juga terdapat siswa yang berasal dari kalangan keluarga mengah keatas, siswa disini memiliki kebiasaan yang berbeda-beda, baik dari cara belajar, bergaul hingga dalam mematuhi tata tertib yang berlaku disekolah, seperti halnya disekolah lain, di SMP Negeri 31 juga mempunyai peraturanperaturan yang harus ditaati oleh setiap siswa. Peraturan ini ditetapkan dengan tujuan agar tercapainya keberhasilan siswa dalam menuntut ilmu. Maka dari itu peneliti tertarik untuk melakukan penelitian dengan Judul "Layanan konseling kelompok dengan Teknik Cinematheraphy untuk meningkatkan kedisiplinan Siswa kelas VII C di SMP Negeri 31 Banjarmasin. Karena layanan teknik cinematheraphy yang dapat membangkitkan rasa semangat pada anak-anak agar tidak bosan saat diberikan layanan konseling kelompok Cinematheraphy. Salah satu tujuan dari Cinematherapy menurut Byrd (dalam Sapiana, 2014) mengidentifkasi "tujuan cinematherapy atau "videowork" sebagai potensi sarana untuk membuka diskusi dalam terapi". Olivia (2010:175) sinema terapi adalah proses menggunakan film bioskop atau televisi untuk tujuan penyembuhan. Terapi ini bisa memberikan efek positif pada banyak orang. Terapi sinema juga merupakan metode yang mudah dilakukan karena dalam pemberian terapi hanya memutarkan film yang bisa membantu cara berpikir 
konseli dan merasakan ketika menghadapi suatu permasalahan yang sama seperti masalah yang dialami oleh konseli agar si konseli dapat memahami dirinya. Film menyajikan potensi kekuatan baru untuk menerangi kedalaman pengalaman manusia. Melalui pelaksanaan menonton film tersebut secara langsung dapat memberikan pemahaman pada siswa akan peran yang ada di dalam alur cerita sehinggaa siswa dapat mengembangkan dirinya untuk memecahkan masalah seperti apa yang ada di dalam alur cerita dari film tersebut.

Penilitian yang menjadi rujukan penliti yakni dari Normanita, Kurniawan, dan Nusantoro (2018) penelitian ini bertujuan untuk mengetahui perbedaan kemampuan interaksi sosial siswa dengan teman sebaya sebelum dan sesudah diberi perlakuan layanan bimbingan kelompok dengan teknik cinematheraphy. Berdasarkan hasil dari perhitungan pretest yakni dapat diketahui bahwa tingkat kemampuan interaksi sosial siswa dengan teman sebaya secara rata-rata sebelum diberi perlakuan layanan bimbingan kelompok dengan teknik cinematherapy memperoleh prosentase sebesar $66 \%$ dan masuk dalam kategori sedang. Berdasarkan pada perhitungan hasil post-test diperoleh hasil ratarata sebasar $79,5 \%$ atau masuk dalam kategori tinggi dengan kata lain telah terjadi peningkatan prosentase sebesar $13,5 \%$ antara sebelum dan sesudah diberi perlakuan layanan bimbingan kelompok dengan teknik cinematherapy.

\section{METODE}

Penelitian ini menggunakan pre- experimental designs atau eksperimen, metode ini tidak memiliki kelompok control dan sample yang digunakan peneliti tidak dipilih secara random. Bentuk designs yang digunakan adalah One-Group Pretest-Posttest Design. Alasan peneliti menggunakan desain ini adalah untuk membandingkan keadaan sample sebelum diberikan treatment dan sesudah diberikan treatment, sehingga desain ini tidak memiliki kelompok control untuk membandingkan keadaan sample peneliti berikan. Dan untuk mengetahui apakah ada perubahan setelah dilakukan penilaian. Penilaian awal (pretest) dilakukan untuk melihat kondisi sample sebelum diberikan treatment dan penilaian akhir (posttest) setelah diberikan perlakuan.

Metode yang digunakan dalam penelitian ini adalah metode non prametrik menggunakan $U j i$ Wilcoxon Match Pairs Test karena mengacu pada variabel data yang dalam penelitian ini adalah variabel ordinal yaitu data yang memiliki jarak dan rangking antara keduanya yang tidak diketahui. Dengan uji Wilcoxon Match Pairs Test tanda-tanda positif dan negatif dari selisih skor pretest dan posttest akan dihitung, Dengan uji Wilcoxon Match Pairs Test tanda-tanda positif dan negatif dari selisih skor pretest dan posttest akan dihitung, dengan begitu kita akan melihat nilai antara pretest dan posttest. Sample yang akan digunakan dalam penelitian ini kurang dari 20 maka cara penghitungan adalah membandingkan jenjang terkecil dari pretest dan posttest.

Populasi dalam penelitian ini adalah seluruh siswa kelas VII C Banjarmasin, yaitu sebanyak 28 respoden dan sampel penelitian sebanyak 8 responden untuk mengukur kedsiplinan siswa sebelum dan sesudah diberikan layanan konseling kelompok dengan teknik Cinematheraphy.

Teknik pengumpulan data yang digunakan dalam penelitian ini yaitu Instrument skala disiplin siswa, indikator menjadi titik tolak untuk menyusun item-item instrumen yang berupa pertanyaan dalam bentuk checklist ataupun pilihan ganda. Kemudian responden mengisi item-item pertanyaan sesuai dengan keadaan yang paling mewakili diri. Semakin tinggi skor nilai yang diperoleh skala disiplin siswa maka semakin tinggi disiplin siswa pada subjek, sebaliknya semakin rendah skor nilai dari skala disiplin siswa maka semakin rendah pula. Skala percaya diri dibagikan pada siswa berisikan pernyataan favorable (pernyataan yang mendukung sikap) dan unfavorable (pernyataan yang tidak mendukung sikap) serta memiliki lima alternatif jawaban dengan masing-masing skor yang berbeda.

Setelah hasil skala diketahui, kemudian direkapitulasi dengan kreteria tingkat kedisiplinan siswa yang ditentukan dengan interval sebagaimana tersebut pada tabel 1 .

Tabel 1. Rentang Nilai

\begin{tabular}{cc}
\hline Rentang & Kriteria \\
\hline $195-240$ & Sangat Tinggi \\
$194-150$ & Tinggi \\
$149-105$ & Sedang \\
$104-60$ & Rendah \\
\hline
\end{tabular}

Teknik analisis data yang digunakan dalam penelitian ini yaitu analisis statistic deskriptif, Analisis deskriptif adalah penelitian yang dilakukan untuk mengetahui nilai variabel independen dan variabel dependen. Analisis deskriptif ini untuk menjawab rumusan masalah tentang bagaimana tingkat kedisiplinan sebelum dilaksanakan konseling kelompok teknik cinematheraphy pada siswa dan bagaimana tingkat kedisiplinan sesudah dilaksanakan konseling kelompok teknik cinematheraphy pada siswa. 
Husnul Khatimah, Farial, Eka Sri Handayani

Jurnal Bimbingan dan Konseling Ar-Rahman

Volume 5, Nomor 2, Tahun 2019

e-ISSN 2477-6300

\section{HASIL DAN PEMBAHASAN}

Berdasarkan penelitian yang telah dilaksanakan, maka dibawah ini akan dipaparkan hasil dari proses penelitian yang dilakukan oleh peneliti meliputi: kedisiplinan siswa sebelum mengikuti layanan konseling kelompok dengan teknik cinematheraphy, kedisiplinan siswa sesudah mengikuti layanan konseling kelompok dengan teknik cinematheraphy, perbedaan kedisiplinan siswa sebelum dan sesudah mengikuti layanan konseling kelompok dengan teknik cinematheraphy, uji wilcoxon dan Pelaksanaan Konseling Kelompok dengan teknik cinematheraphy.

Berdasarkan hasil penelitian dan pembahasan tetang Layanan Konseling Kelompok Dengan Teknik Cinematheraphy Untuk Meningkatkan Kedsiplinan Siswa Kelas VII C di SMP Negeri 31 Banajrmasin. Dapat disimpulakan sebelum diberikan treatment kedisiplinan siswa berada dalam katagori rendah dan setelah diberi treatment berada dalam katagori tinggi.
Berikut distribusi kedisiplinan siswa sebelum diberikan dan sesudah diberikan layanan konseling kelompok dengan teknik cinematheraphy:

Tabel 2. Kedisiplinan Siswa Sebelum (Pretest) dan Sesudah (Posttest)

\begin{tabular}{ccccc}
\hline Nama & Pretest & Kategori & Posttest & Kategori \\
\hline AS & 96 & Rendah & 110 & Sedang \\
AN & 85 & Rendah & 112 & Sedang \\
F & 75 & Rendah & 130 & Sedang \\
MA & 75 & Rendah & 125 & Sedang \\
RA & 78 & Rendah & 118 & Sedang \\
SA & 104 & Rendah & 144 & Sedang \\
PS & 73 & Rendah & 109 & Sedang \\
YH & 65 & Rendah & 107 & Sedang \\
\hline Total & $\mathbf{6 5 1}$ & & $\mathbf{9 5 5}$ & \\
\hline
\end{tabular}

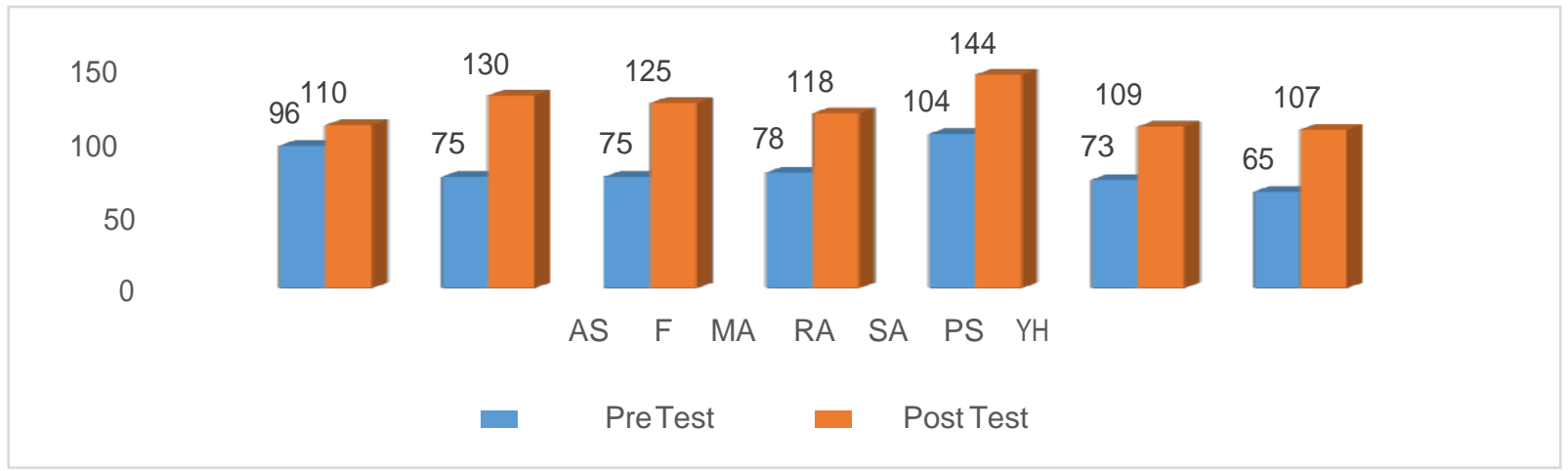

Gambar 1. Grafik Prestest dan Posttest

Berdasarkan hasil dari pretest dan posttest maka dapat disimpulkan bahwa progres atau hasil dari layanan konseling kelompok cinematheraphy kelompok hasil untuk meningkatkan kedisiplinan pada siswa. Untuk melihat hasil statistik jika nilai sig < 0,05 maka berhubungan nilai $Z_{\text {tabel }}$ untuk nilai sig 0,05 $=-2.524$.

Tabel 3. Hasil Uji Wiilcoxon

\begin{tabular}{cc}
\hline & Sesudah - sebelum \\
\hline $\mathrm{Z}$ & $-2.524^{\mathrm{b}}$ \\
Asymp. Sig. & 0,012 \\
(2-tailed) & \\
\hline
\end{tabular}

Untuk melihat hasil statistik jika nilai sig < 0,05 maka berhubungan nilai $Z_{\text {tabel }}$ untuk nilai sig 0,05 $=-2.524$. berdasarkan hasil perhitungan uji wilcoxon menggunakan SPSS maka diperoleh $\mathrm{Z}_{\text {tabel }}$ untuk nilai sig 0,012 jadi $Z_{\text {hitung }}$ sebesar -2.524 , karena nilai ini adalah mutlak sehingga tanda negatif tidak diperhitungkan. Maka dari itu nilai $\mathrm{Z}_{\text {hitung }}$ menjadi
2.524. selanjutnya nilai $Z_{\text {hitung }}$ ini dibandingkan dengan nilai $Z_{\text {tabel }}$ dengan taraf signifikasi $8 \%$, harga $\mathrm{Z}_{\text {tabel }}=0$. Maka $\mathrm{Z}_{\text {hitung }}=2.524>\mathrm{Z}_{\text {tabel }}=0$ maka Ha dterima dengan demikian tingkat kedisiplinan terdapat perubahan setelah diberikan layanan konseling kelompok dengan teknik cinematheraphy dilihat dari ketentuan $Z_{\text {hitung }}>Z_{\text {tabel }}$ dan Ho ditolak. Jadi dapat disimpulkan bahwa layanan konseling kelompok dengan teknik cinematheraphy dapat meningkatkan kedisiplinan dari yang rendah menjadi sedang pada siswa kelas VII C SMP Negeri 31 Banjarmasin.

Pelaksanaan kegiatan layanan konseling kelompok dengan menggunakan teknik cinematheraphy untuk meningkatkan kedisiplinan siswa yang dilaksanakan selama 6 kali pertemuan. 1 kali pertemuan untuk pretest dan 4 kali pemberian layanan terakhir 1 kali angket untuk postes, Sebelum memulai sesi konseling kelompok, peneliti bersama dengan siswa melakukan komitmen konseling kelompok. Kontrak ini juga dilaksanakan dalam rangka membangun rapport dengan seluruh peserta

Dipublikasikan Oleh : 
Husnul Khatimah, Farial, Eka Sri Handayani

Jurnal Bimbingan dan Konseling Ar-Rahman

Volume 5, Nomor 2, Tahun 2019

e-ISSN 2477-6300

didik yang menjadi sampel subjek penelitian.

Kontrak dalam konseling kelompok di mulai dengan mengumpulkan siswa yang termasuk dalam katagori tingkat kepercayaam diri yang rendah, di dalam konseling ada 8 siswa yang ikut serta dalam kegiatan konseling kelompok.

Menurut Solomon (dalam Hidayat 2018:69) berpendapat bahwa Cinematheraphy telah muncul sebagai intervensi berkhasiat bagi orang dewasa, remaja, dan anak-anak. Dengan melihat dan mendisukusikan film, klien dan terapis dapat mengakses konten bermakna metaforis untuk proses pekerjaan termasuk di dalam belajar selanjutnya menurut Suarez (dalam Gibson \& Michelle, 2011) cinematheraphy adalah proses menggunakan film dalam terapi sebagai metafora untuk meningkatkan pertumbuhan dan wawasan klien.

Dengan hal ini dapat dibuktikan bahwa layanan konseling kelompok dengan teknik Cinematheraphy sebagai metafora untuk meningkatkan pertumbuhan dan wawasan klien, hal ini ditandai dengan meningkatnya kedisiplinan siswa di SMP Negeri 31 Banjarmasin, dimana sebelum dilaksanakan konseling kelompok teknik cinematheraphy kedisiplinan siswa masih berada pada kategori rendah dan sesudah dilaksanakan layanan konseling kelompok teknik cinematheraphy kedisiplinan siswa berada di kategori sedang. Berarti hal ini menunjukkan adanya peningkatan yang siginifikan terhadap kedisiplinan siswa kelas VII C di SMP Negeri 31 Banjarmasin, hal ini sesuai dengan penelitian yang dilakukan oleh Wijayanti (2018) dengan judul Pengaruh Teknik Cinematheraphy dalam bimbingan kelompok untuk meningkatkan disiplin siswa kelas XI di SMK Kartanegara kediri tahun ajaran 2017/2018 yang hasilnya Dari uji paired sample $t$-test diperoleh nilai sig.(2-tailed) $0,000<0,05$. Hal ini juga dibuktikan dari nilai thitung $>t$ tabel atau 9,679>2,262 sehingga dapat disimpulkan ada pengaruh teknik cinematherapy dalam bimbingan kelompok terhadap disiplin siswa.

\section{PENUTUP}

Berdasarkan hasil penelitian dapat disimpulkan bahwa layanan konseling kelompok dengan teknik cinematheraphy dapat meningkatkan kedisiplinan dari yang rendah menjadi sedang pada siswa kelas VII C SMP Negeri 31 Banjarmasin. Adapun saran dari peneliti yaitu: (1) Bagi Guru BK Hasil penelitian ini menunjukkan bahwa konseling kelompok teknik cinematheraphy mampu memberikan peningkatan kedisiplinan siswa, maka saran yang dapat diberikan kepada guru BK yakni dengan keterbatasan peneliti kesediaan untuk menerapkan konseling kelompok teknik cinematheraphy dalam sesi pembelajaran untuk siswa yang memiliki tingkat kedisipinan yang rendah. (2) Bagi Siswa diharapkan siswa dapat meningkatkan kedisiplinan disekolah maupun kehidupan sehari-hari, serta diharapkan siswa agar selalu mematuhi tata tertib yang berlaku disekolah. (3) Bagi Peneliti Selanjutnya agar menggunakan waktu sebaaik-baiknya dan diharapkan kepada peneliti selanjutnya untuk melaksanakan konseling kelompok cinematheraphy dengan metode yang terbaru atau dengan hal-hal yang berbeda dari konseling kelompok yang sudah dilaksanakan para peneliti lain dan kepada peneliti selanjutnya agar menggunakan media yang lebih memadai lagi seperti penggunaan media LCD Proyektor agar proses konseling kelompok teknik cinematheraphy dapat terlaksana dengan efektif.

\section{REFERENSI}

Gibson, R.L., Michelle, M.H. (2011). Bimbingan dan Konseling. Yogyakarta: Pustaka Pelajar.

Handoyo, E. (2008). Pendidikan Anti Korupsi. Widya karya: Semarang

Normanita, R., Kurniawan, K., \& Nusantoro, E. (2018). Meningkatkan Interaksi Sosial dengan Teman Sebaya Melalui Layanan Bimbingan Kelompok dengan Teknik Cinematherapy. Indonesian Journal of Guidance and Counseling: Theory and Application, 7(3), 1-7.

Noviani, P. (2012). Meningkatkan Kedisiplinan Belajar Siswa Dengan Konseling Kelompok Pada Siswa Kelas X Sma Negeri 1 Kalirejo. Skripsi. Lampung: Universitas Lampung.

Olivia, F. (2010). Mengoptimalkan Otak Supaya Awet Muda. Jakarta: PT. Elex Media Komputindo.

Purwanto, N. (1998). Psikologi Pendidikan. Bandung : PT. Remaja Rosda.

Sapiana. (2014). Pengaruh Bimbingan Kelompok Teknik Cinema therapy Terhadap Motivasi Belajar Siswa Kelas X Multimedia Di SMK Negeri 1 Limboto Kabupaten Gorontalo. Other Thesis, Universitas Negri Gorontalo. (online). Diakses tanggal 21 Mei 2016.

Solomon, G. (2001). Reel therapy: How movies inspire you to overcome life's problems. BookBaby

Tarmizi. (2013). Meningkatkan Kemampuan Menulis Puisi Siswa dengan Teknik Pemodelan di Kelas VIID SMP Negeri 19 Kota Bengkulu. Tesis. Bengkulu: Universitas Bengkulu.

Wijayanti, R.D. (2018). Pengaruh teknik cinematheraphy dalam bimbingan kelompok untuk meningkatkan kedisiplinan siswa kelas XI di SMK Kartanegara kediri. Skripsi. Kediri: Universitas Nusantara PGRI Kediri. 